\title{
Immobilization in Spheres of a Cocktail Rich in Xylanase Produced by the Fungus Fusarium sp. EA 1.3.1 for Hydrolysis of Sugarcane Bagasse
}

\author{
Alice Gomes Miranda1, Tarcisio Michael Ferreira Soares de Oliveira², \\ Rosymar Coutinho de Lucass,4, David Lee Nelson', Juan Pedro Bretas Roa², \\ Vivian Machado Benassi ${ }^{*}$
}

\footnotetext{
${ }^{1}$ Programa de Pós-Graduação em Biocombustíveis, Universidade Federal dos Vales do Jequitinhonha e Mucuri, campus JK, Diamantina, Minas Gerais, Brazil

${ }^{2}$ Instituto de Ciência e Tecnologia, Universidade Federal dos Vales do Jequitinhonha e Mucuri campus JK, Diamantina, Minas Gerais, Brazil

${ }^{3}$ Instituto de Ciências Biológicas, Departamento de Parasitologia, Microbiologia e Imunologia, Universidade Federal de Juiz de Fora, Minas Gerais, Brazil

${ }^{4}$ Faculdade de Medicina de Ribeirão Preto, Departamento de Bioquímica, Universidade de São Paulo, Ribeirão Preto, São Paulo, Brazil

Email: *vivian.benassi@ict.ufvjm.edu.br
}

\begin{abstract}
How to cite this paper: Miranda, A.G., de Oliveira, T.M.F.S., de Lucas, R.C., Nelson, D.L., Roa, J.P.B. and Benassi, V.M. (2021) Immobilization in Spheres of a Cocktail Rich in Xylanase Produced by the Fungus Fusarium sp. EA 1.3.1 for Hydrolysis of Sugarcane Bagasse. Advances in Bioscience and Biotechnology, 12, 436-457. https://doi.org/10.4236/abb.2021.1212028
\end{abstract}

Received: October 7, 2021

Accepted: December 14, 2021

Published: December 17, 2021

Copyright $\odot 2021$ by author(s) and Scientific Research Publishing Inc. This work is licensed under the Creative Commons Attribution International License (CC BY 4.0).

http://creativecommons.org/licenses/by/4.0/ (c) (i) Open Access

\begin{abstract}
Second generation ethanol is produced from the degradation of lignocellulosic biomass using enzymes as catalysts, with emphasis on xylanases. These biocatalysts are often costly, but stable at high temperatures, and their reuse is of great value, so the immobilization of the enzymes can increase their applicability on an industrial scale. We sought to immobilize a cocktail rich in xylanase produced by the fungus Fusarium sp. EA 1.3.1 in alginate spheres, optimize the immobilization method, characterize the immobilized derivatives, improve their physical-chemical characteristics, and perform the hydrolysis of sugarcane bagasse to release sugars. The Fusarium sp. EA 1.3.1 has been identified and used for cocktail rich in xylanase production that was immobilized in alginate spheres. During this process, the drip equipment, and the concentration of the solutions of sodium alginate and calcium chloride were evaluated. The best results were obtained with the glass rod and with concentrations of $3.14 \%$ and $2.10 \%$ for the solutions, respectively. The apparent optimum conditions of $\mathrm{pH}$ and temperature reaction were studied, and the values of $\mathrm{pH} 6.5$ and $60^{\circ} \mathrm{C}$ were obtained. The immobilized conjugate also presented greater stability at this temperature than that of the soluble cocktail. The conjugate could be recycled up to six times, and its activity was maintained after 75 days of storage. Finally, the hydrolysis in natural sugarcane
\end{abstract}


bagasse was achieved, and greater amounts of reducing sugars were obtained in the reaction with the conjugate. Thus, the cocktail rich in xylanase produced by the fungus Fusarium $s p$. EA1.3.1 was successfully immobilized on alginate spheres and possesses the potential to be used as a catalyst in industrial processes such as the lignocellulosic ethanol industry.

\section{Keywords}

Xylanase Cocktail, Spheres Immobilization, Lignocellulolytic Enzymes, Biomass Hydrolysis

\section{Introduction}

Fossil fuels are an exhaustible source of energy, its massive exploitation and consequent depletion of available natural reserves cause a negative impact on the environment preservation [1]. An attempt to reduce this impact is the use of alternative sources of energy. Biofuels stand out for being environmentally favorable and highly energy efficient, competing with or serving as additives for fossil fuels [2]. In Brazil, for example, a mixture of $27 \%$ ethanol in gasoline has been mandatory since 1993 [3].

The continued growth of the population, as well as the "food versus fuel" debate, has directed research towards production of biofuels from raw material that is not used for food purposes [4] [5]. Thus, lignocellulosic biomass, which is one of the most carbon-neutral resources and recyclable, has been used to produce renewable energy and, therefore, bioethanol. Research has been performed to enable the commercial production of second generation ethanol $(2 \mathrm{G})$ or cellulosic ethanol from industrial waste, such as sugarcane bagasse, [6] [7].

The rich polymeric composition of sugars in lignocellulosic biomass is the factor that contributes to its high potential in bioenergy conversion, which is a complex structure composed mainly of three fractions with a high energy content called cellulose ( $40 \%$ to $45 \%$ ), hemicellulose (30\% to $35 \%$ ) and lignin ( $20 \%$ to $30 \%)$. However, this structural complexity also causes difficulties for its hydrolysis [6]. Enzyme-based hydrolysis is an eco-friendly procedure for producing small sugars that can be converted in biofuels [7] [8], such as the use of xylanases to break down xylans, the main constituent of hemicellulose, into xylose, which can be converted to ethanol by yeasts specialized in the fermentation of 5 carbon sugars. This is a major challenge for the economic viability of the second generation process, because of the high cost of enzymes production [9] [10].

Conventional production of bioethanol is generally accomplished using systems of free enzymes. To improve the efficiency of this process, enzyme immobilization has been proposed to ensure the stability of enzymes, providing improvements in this industrial process. In addition, the possibility of recovery and reuse makes the application of this technique economically viable [11] [12].

Other advantages of immobilized enzymes are high resistance to changes in 
the reaction environment, high thermal and $\mathrm{pH}$ stability, easier separation of the catalyst and reaction product, increased productivity and ethanol yield, increased tolerance to a high concentration of substrate, less inhibition by final products, increased specificity, and greater storage stability than those of the soluble enzyme. Furthermore, the enzyme is not directly exposed to an external agent that can cause denaturation and inhibition [13]-[18]. One of the most accessible, rapid, non-toxic, immobilization supports, with good mechanical resistance and less expensive procedures, is sodium alginate. It is immobilized by encapsulating the enzyme in the presence of calcium chloride [19] [20] [21].

Based on this information, this research aimed to immobilize an enzyme cocktail rich in xylanase produced by the filamentous fungus Fusarium $s p$. EA 1.3.1 in alginate spheres, standardize the immobilization method, biochemically characterize the immobilized derivatives, and verify the efficiency of the derivative for the hydrolysis of in natural sugarcane bagasse. The consequence is the release of sugars susceptible to alcoholic fermentation for use in the cellulosic ethanol industry.

\section{Material and Methods}

The tests were conducted at the Laboratory of Mycology, Enzymology and Product Development (LMEDP), Institute of Science and Technology (ICT), Federal University of the Jequitinhonha and Mucuri Vales (UFVJM), Diamantina, Minas Gerais, Brazil. The microorganism was registered in the National System for the Management of Genetic Heritage and Associated Traditional Knowledge (SisGen), number A64AD93.

\subsection{Maintenance of the Filamentous Fungus Fusarium sp. EA 1.3.1}

The filamentous fungus Fusarium sp. EA 1.3.1 was kept in tubes containing 4\% (w/v) Quaker ${ }^{\circledR}$ oat solid medium and $2 \%(w / v)$ Bacteriological Agar [22], at $4^{\circ} \mathrm{C}$. The fungus strain was kept on silica gel, where a spore suspension was prepared in $3 \mathrm{~mL}$ of powdered milk (200 g. $\mathrm{L}^{-1}$ of distilled water). Approximately $1 \mathrm{~mL}$ of this suspension was added to test tubes containing $7 \mathrm{~g}$ of silica gel, stirred, sealed, and stored at $4^{\circ} \mathrm{C}$.

\subsection{Inoculum}

The cultures of the fungus stored in tubes containing solid medium [22] were suspended in $8 \mathrm{~mL}$ of sterile distilled water, and a $1 \mathrm{~mL}$ aliquot of the spore suspension $\left(2.5 \times 10^{7}\right.$ conidia $\left.\mathrm{mL}^{-1}\right)$ was inoculated in $125 \mathrm{~mL}$ Erlenmeyer flasks containing $25 \mathrm{~mL}$ of modified Khanna medium ( $1.00 \mathrm{~g}$ of wheat bran; $0.10 \mathrm{~g}$ of yeast extract; $0.03 \mathrm{~g}$ of $\mathrm{KH}_{2} \mathrm{PO}_{4} ; 0.05 \mathrm{~g}$ of $\mathrm{Mg} \cdot \mathrm{SO}_{4} \cdot 7 \mathrm{H}_{2} \mathrm{O}$ and distilled water to 100 $\mathrm{mL}$ ), with an initial $\mathrm{pH}$ of 8.5. The samples were kept in a bacteriological incubator under static conditions at $30^{\circ} \mathrm{C}$ for four days [23] [24]. The crude soluble enzyme extract was obtained by filtering through a Büchner funnel with the aid of a Prismatec ${ }^{\circledR}$ vacuum pump and stored at $4^{\circ} \mathrm{C}$ for later immobilization. 


\subsection{Determination of Xylanolytic Activity by the Saccharification Method}

The activity was determined by measuring the amount of reducing sugars formed by the enzymatic hydrolysis of the Sigma ${ }^{\circledR}$ beechwood xylan used as a substrate [25]. The enzyme immobilized on alginate spheres was incubated with $1000 \mu \mathrm{L}$ of beechwood xylan at a concentration of $1 \%(\mathrm{~m} / \mathrm{v})$ in $100 \mathrm{mM}$ sodium phosphate buffer, $\mathrm{pH} 6.5$, in a water bath at $60^{\circ} \mathrm{C}$ for 5 minutes. After this time, 200 $\mu \mathrm{L}$ aliquots were removed and added to $200 \mu \mathrm{L}$ of DNS reagent. Immediately after the addition of the immobilized enzyme extract with the substrate, an aliquot of the mixture was removed and added to $200 \mu \mathrm{L}$ of the DNS reagent. This sample represented zero time. Subsequently, the tubes were boiled for 5 minutes, and, after cooling, $2 \mathrm{~mL}$ of distilled water was added. The readings were performed at $540 \mathrm{~nm}$ in a RayLeigh UV-2601 ${ }^{\circledR}$ spectrophotometer, against the zero-reaction time, in which spontaneous hydrolysis of the substrate was minimal. The system was standardized using a xylose standard curve of 0.1 to $0.6 \mathrm{mg} / \mathrm{mL}$. The unit of enzymatic activity corresponded to the number of micromoles of reducing sugar that was formed per minute under the test conditions, the activity was expressed in $\mathrm{mU}$.

Amylolytic and celulolytic activity were also determined by the same method, using $1 \%(\mathrm{w} / \mathrm{v})$ starch substrate in $100 \mathrm{mM}$ sodium acetate buffer, $\mathrm{pH} 5.0$ to the amylase, $2 \%(\mathrm{~m} / \mathrm{v})$ CMC substrate in $100 \mathrm{mM}$ sodium citrate buffer $\mathrm{pH} 4.8$, and $1 \%$ $(\mathrm{m} / \mathrm{v})$ Avicel em $100 \mathrm{mM} 100 \mathrm{mM}$ sodium citrate buffer $\mathrm{pH} 4.8$ to the cellulases.

\subsection{Immobilization of the Cocktail Rich in Xylanase in Alginate Spheres}

\subsubsection{Process of Formation of Alginate Spheres in Calcium Chloride Solution}

The $10 \mathrm{~mL}$ solution containing $3 \%(\mathrm{~m} / \mathrm{v})$ Isofar ${ }^{\circledR}$ sodium alginate $(\mathrm{NaAlg})$ and crude soluble enzyme extract was dripped into $20 \mathrm{~mL}$ of a $4 \%(\mathrm{~m} / \mathrm{v})$ aqueous solution of calcium chloride with mechanical stirring. After the formation of the immobilized spheres containing the xylanolytic cocktail, the beads were separated from the calcium chloride solution, washed using $10 \mathrm{mM}$ sodium phosphate buffer, $\mathrm{pH} 6.5$, and stored at $4^{\circ} \mathrm{C}$.

\subsubsection{Testing the Drip Instrument for the Formation of Immobilized Spheres}

Different instruments for dripping and bead formation were tested, these being a graduated volumetric pipette $(10 \mathrm{~mL})$, Pasteur plastic pipette, a thick glass rod $(1.0 \mathrm{~cm}$ in diameter) and a thin glass $\mathrm{rod}(0.5 \mathrm{~cm}$ in diameter). The spheres were formed according to method 2.4.1 and subjected to activity dosage of xylanase.

\subsubsection{Determination of the Effect of the Concentration of Sodium Alginate and Calcium Chloride on the Immobilization Process through Factorial Planning}

The influence of the concentrations of sodium alginate and calcium chloride on 
the formation of the immobilization spheres was analyzed by means of an experimental design through a Central Rotational Composite Design with two independent variables $\left(\mathrm{DCCR}^{2}\right), X_{1}$ : concentration of alginate of sodium, and $X_{2}$ : calcium chloride concentration, totaling 11 tests, 3 central points and 4 tests distributed rotationally (axial points) at a distance $\alpha$ from the central point. The orthogonal $\alpha$ value was 1.41 [26] [27]. The variables were used at their upper $(+1)$ and lower $(-1)$ levels, with central points of $X_{1}[\mathrm{Alg}]=2.5 \%$ and $X_{2}[\mathrm{Cl}]=5.0 \%$. The results obtained for the activities were analyzed with the Protimiza Experimental Design ${ }^{\circledR}$ software (Table 1).

\subsection{Effect of pH and Temperature on Enzyme Activity}

The immobilized xylanolytic cocktail was characterized biochemically using experimental planning through a Central Rotational Composite Design with two independent variables $\left(\mathrm{DCCR}^{2}\right)$, these being $X_{1}=\mathrm{pH}$ and $X_{2}=$ temperature $\left({ }^{\circ} \mathrm{C}\right)$ of the reaction medium, totaling 11 tests, 3 central points and 4 tests rotationally distributed (axial points) at a distance $\alpha$ from the central point. The central $\mathrm{pH}$ values were 6.5 , with an interval of 1.5 , and a temperature of $60^{\circ} \mathrm{C}$, with intervals of $20^{\circ} \mathrm{C}$ (Table 2 ).

\subsection{Temperature Stability}

The temperature stability was evaluated by incubating them for 1, 5, 7, 14 and 24 hours in the absence of substrate at $50^{\circ} \mathrm{C}, 60^{\circ} \mathrm{C}$ and $70^{\circ} \mathrm{C}$. The samples were removed, placed in an ice bath, and the determination of the enzymatic activity of each sample under ideal conditions of $\mathrm{pH}$ and temperature was performed.

Table 1. Experimental design with the value of solutions concentration.

\begin{tabular}{ccccc}
\hline Designer & $X_{1}$ & $X_{2}$ & $\begin{array}{c}X_{1}=\text { alginate of sodium } \\
\text { concentration (\%) }\end{array}$ & $\begin{array}{c}X_{2}=\text { calcium chloride } \\
\text { concentration (\%) }\end{array}$ \\
\hline 1 & -1 & -1 & 1.50 & 3.00 \\
2 & 1 & -1 & 3.50 & 3.00 \\
3 & -1 & 1 & 1.50 & 7.00 \\
4 & 1 & 1 & 3.50 & 7.00 \\
5 & -1.41 & 0 & 1.09 & 5.00 \\
6 & +1.41 & 0 & 3.91 & 5.00 \\
7 & 0 & -1.41 & 2.50 & 2.17 \\
8 & 0 & +1.41 & 2.50 & 7.83 \\
9 & 0 & 0 & 2.50 & 5.00 \\
10 & 0 & 0 & 2.50 & 5.00 \\
11 & 0 & 0 & 2.50 & 5.00 \\
\hline
\end{tabular}


Table 2. Experimental design with the value of $\mathrm{pH}$ and temperature.

\begin{tabular}{ccccc}
\hline Designer & $X_{1}$ & $X_{2}$ & $X_{1}=\mathrm{pH}$ & $X_{2}=\mathrm{T}\left({ }^{\circ} \mathrm{C}\right)$ \\
\hline $\mathbf{1}$ & -1 & -1 & 5.0 & 40 \\
2 & 1 & -1 & 8.0 & 40 \\
$\mathbf{3}$ & -1 & 1 & 5.0 & 80 \\
$\mathbf{4}$ & 1 & 1 & 8.0 & 80 \\
$\mathbf{5}$ & -1.41 & 0 & 4.4 & 60 \\
$\mathbf{6}$ & +1.41 & 0 & 8.6 & 60 \\
7 & 0 & -1.41 & 6.5 & 32 \\
$\mathbf{8}$ & 0 & +1.41 & 6.5 & 88 \\
9 & 0 & 0 & 6.5 & 60 \\
10 & 0 & 0 & 6.5 & 60 \\
11 & 0 & 0 & 6.5 & 60
\end{tabular}

\subsection{Analysis of the Effect of Glucose and Xylose on the Activity of the Immobilized Cocktail Rich in Xylanase}

The activation or inhibition of the activity in the presence of different concentrations of 5 and $10 \mathrm{mM}$ of D-xylose Sigma-Aldrich ${ }^{\circledR}$ and D-glucose Isofar ${ }^{\circledR}$ during the reaction with the beechwood xylan as substrate. The control was the reaction in the absence of xylose or glucose.

\subsection{Recycling Test of the Xylanase Rich Cocktail Immobilized on Alginate Spheres}

The number of times the alginate spheres with the immobilized cocktail could be reused in the enzymatic reaction was determined. After the reaction, the beads were filtered, washed using $10 \mathrm{mM}$ sodium phosphate buffer, $\mathrm{pH}$ 6.5, and incubated in the same solution for one minute, followed by a new measurement of xylanolytic activity.

\subsection{Analysis of Xylanolytic Activity after Storage at $4^{\circ} \mathrm{C}$}

To verify the stability of the free and immobilized forms of the enzyme, both were stored for up to 75 days at $4^{\circ} \mathrm{C}$, and the activity was measured.

\subsection{Hydrolysis of Raw Sugarcane Bagasse}

The hydrolysis of the sugarcane bagasse was achieved by stirring the samples in a $125 \mathrm{~mL}$ Erlenmeyer flask at $60^{\circ} \mathrm{C}$ for 24 hours using: 1) soluble enzyme, and 2) enzyme immobilized in alginate. The first sample contained $0.2 \mathrm{~g}$ of raw sugarcane bagasse together with $10 \mathrm{~mL}$ of $100 \mathrm{mM}$ sodium acetate buffer solution, $\mathrm{pH}$ 5.5 , and $10 \mathrm{~mL}$ of soluble crude enzyme extract. The second reaction contained $0.2 \mathrm{~g}$ of sugarcane bagasse, $20 \mathrm{~mL}$ of $100 \mathrm{mM}$ sodium phosphate buffer solution, pH 6.5, plus 80 spheres of alginate with the immobilized xylanase rich cocktail.

After the enzymatic hydrolysis of the sugarcane bagasse, the solid portion was filtered using a vacuum pump, dried and taken to the Scanning Electron Micro- 
scope (SEM). The particle morphology of the samples was evaluated using a HITACHI TM3000 SEM (Japan) operated at $15 \mathrm{kV}$. The samples were attached to a double-sided tape over a stub with a diameter of $2 \mathrm{~cm}$ and a height of $1 \mathrm{~cm}$.

\section{Results and Discussions}

\subsection{Determination of the Drip Instrument for the Formation of Immobilized Spheres Containing the Cocktail Rich in Xylanase}

The use of the thick glass rod, $1.0 \mathrm{~cm}$ in diameter, was the best method for dripping the solution containing the xylanolytic cocktail and sodium alginate to form the spheres, a factor determined by the higher yields of the conjugate's xylanolytic activity, corresponding to $52.3 \%$ of the soluble enzyme activity. The second most efficient method involved the use of the Pasteur plastic pipette, which yielded an activity equivalent to $8.8 \%$ that of the soluble enzyme. The activity obtained using the graduated glass pipette was $4.53 \%$ that of the soluble enzyme. The thin glass rod was not verified with the immobilized derivative. In addition, the spheres formed using the thick glass rod were more uniform and more spherical than those obtained with other equipments (Figure 1).

The production of spherical calcium alginate particles appears to be simple from a theoretical point of view, but, in practice, it is a complex process. For the spheres to be standardized in terms of size, shape, surface morphology and mechanical stability, several factors that interfere with their formation must be analyzed. We can mention the equipment used for the drip, the height and speed of the dripping, the formulation, preparation and concentration of the alginate and gelation solutions, production conditions and post-production treatment [23] [24].

The extrusion drip is the most widely applied and the simplest method for the formation of calcium alginate spheres in liquid air systems [26] [27] [28]. Without contradicting the author's idea that extrusion would be the most widely applied method, in this study we opted to test even simpler equipment, such as the thick glass rod, the thin glass rod, the Pasteur pipette and the graduated glass pipette. These would not be suitable for large-scale production of course, but for the purpose of laboratory studies, the result in the formation of spheres was satisfactory. In addition, no investment in the acquisition of materials or equipment was necessary.
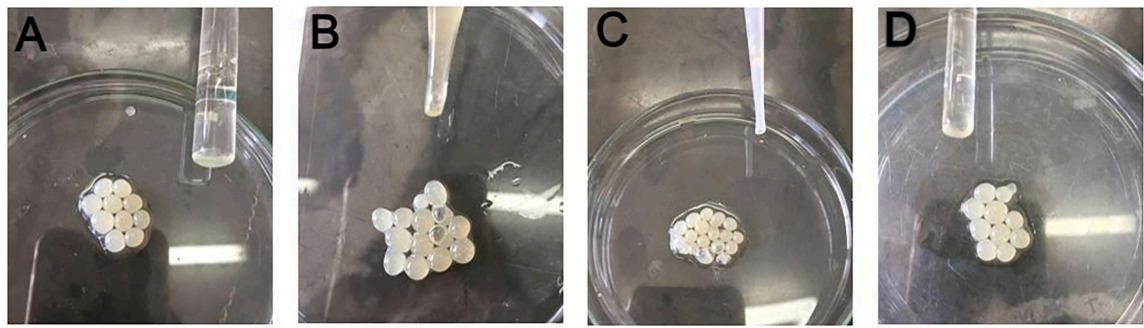

Figure 1. Immobilized spheres formed with drip instruments. (A) Thick glass rod, (B) graduated glass pipette, (C) Pasteur plastic pipette, (D) thin glass rod. 


\subsection{Analysis of the Concentration of Sodium Alginate and Calcium Chloride in the Immobilization of the Cocktail Rich in Xylanase}

By varying the concentration of the sodium alginate solution containing the crude soluble xylanolytic extract and the aqueous calcium chloride solution, an activity of $222 \mathrm{mU}$ was obtained (Table 1), with NaAlg 2.50\% and $\mathrm{CaCl}_{2} 2.17 \%$. On the other hand, the lowest activity, $58 \mathrm{mU}$, was obtained for the concentrations of $\mathrm{NaAlg}$ and $\mathrm{CaCl}_{2}$ of $1.50 \%$ and $7.00 \%$, respectively.

A statistical analysis of the catalytic behavior of the immobilized xylanase-rich cocktail was performed. The parameters of significance and non-significance, as well as the levels of significance are shown in Table 3.

The experimental results were evaluated through a regression analysis expressed in Equation (1), which evaluates the xylanolytic activity $(\mathrm{U} / \mathrm{mL})$ as a function of the concentration of sodium alginate $\left(x_{1}\right)$, and calcium chloride $\left(x_{2}\right)$. The significance and non-significance parameters, as well as the significance level values are shown in Table 3. The elimination of non-significant parameters with a p-value greater than 0.05 is an interesting alternative to simplify the model because they present little or no influence on the final adjustment result. Thus, when analyzing the result expressed in Table 3 and in the Pareto graph, the coded values of $x_{2}^{2}$, e $x_{1}-x_{2}$ were removed from the model, and it was recalculated mathematically within the region evaluated by the Central Composite Planning.

$$
Y_{1}=149.47+24.31 x_{1}-18.25 x_{1}^{2}-46.93 x_{2}
$$

The F-value calculated for the quadratic regression model was 65.3, that is, greater than the tabulated F3.7 value (4.35) $\left(F_{\text {Calc }}>F_{\text {tab }}\right)$ in the $95 \%$ confidence interval. Degrees of freedom of regression and residuals were removed from ANOVA, and the model was considered statistically significant according to the $\mathrm{F}$ test. In addition, the model presented a good determination coefficient, with $\mathrm{R}^{2}$ nearly $0.98 \%$, which represents a proximity between experimental results and predicted theoretical values.

Table 3. Regression coefficient for the activity response of xylanolytic conjugates.

\begin{tabular}{ccccccccc}
\hline \multirow{2}{*}{ Name } & \multicolumn{2}{c}{ Coefficient } & \multicolumn{2}{c}{ Standard Error } & \multicolumn{2}{c}{ T calculated } & \multicolumn{2}{c}{ p-value } \\
\cline { 2 - 8 } & Before & After & Before & After & Before & After & Before & After \\
\hline Average & 142.16 & 149.47 & 5.64 & 4.69 & 25.20 & 31.88 & 0.0000 & 0.0000 \\
$x_{1}$ & 24.31 & 24.31 & 3.46 & 3.95 & 7.04 & 6.15 & 0.0009 & 0.0005 \\
$x_{1}^{2}$ & -15.97 & -18.25 & 4.11 & 4.49 & -3.88 & -4.07 & 0.0116 & 0.0048 \\
$x_{2}$ & -46.93 & -46.93 & 3.46 & 3.95 & -13.58 & -11.89 & 0.0000 & 0.0000 \\
$x_{2}^{2}$ & 7.76 & - & 4.11 & - & 1.89 & - & 0.1177 & - \\
$x_{1}-x_{2}$ & 3.69 & - & 4.89 & - & 0.75 & - & 0.4844 & - \\
\hline
\end{tabular}

Software Protimiza. 
The response surface of the influence of $\mathrm{NaAlg}$ and $\mathrm{CaCl}_{2}$ concentrations on the immobilization process demonstrated that the highest activities were in the range of $2 \%$ to $4 \%$ for $\mathrm{NaAlg}$, and the maximum activity value was $3.14 \%$, and $\mathrm{CaCl}_{2}$ the value was $2.10 \%$ (Figure 2 ).

No spheres were formed at very low NaAlg concentrations. Moreover, in other factorial designs, the solution became very viscous at very high concentrations of NaAlg, which made dripping difficult. The variation in the concentration of the $\mathrm{NaAlg}$ solution was from $1.00 \%$ to $6.00 \%$. The concentration of the $\mathrm{CaCl}_{2}$ solution also interfered in the formation of the spheres, because of the saturation of the solution when subjected to the formation of many spheres.

According to Lee et al. [23], alginate solutions with high viscosities are not suitable for encapsulation applications because of difficulties in the process of sphere formation. On the other hand, there is no formation of spherical calcium alginate particles at lower viscosities because drops are deformed when colliding with the gelling solution. When the drop enters the gelling solution, the viscous forces within the drop act to maintain its spherical shape, whereas the drag forces exerted on the surface of the drop from the surrounding solution tend to hinder the formation of the granule [29]. Drops of alginate solution with lower viscosities are less able to retain their spherical properties against the drag forces after collision with the surface of the calcium chloride bath.

Sukri and Sakinah [30] showed that the effect of the NaAlg concentration on enzyme activity and immobilization yield at the $0.3 \mathrm{M} \mathrm{CaCl}_{2}$ concentration was at a maximum at the $3.0 \% \mathrm{NaAlg}$ concentration, and it decreased when the alginate concentration increased to $4.0 \%$ and $5.0 \%$, which corroborates the result found in that study. Values similar to those observed by Kumar et al. [31], whose optimal concentrations of $\mathrm{NaAlg}$ was $3.0 \%$ and that of $\mathrm{CaCl}_{2}$ was $0.2 \mathrm{M}$ when immobilizing xylanase produced by Bacillus amyloliquefaciens.

Jampala and collaborators [20] performed a factorial design with several variables, including concentration of sodium alginate and calcium chloride, and concluded that all the contours of sodium alginate were slightly inclined in relation to the other variables, indicating that NaAlg has a more significant influence than the calcium chloride concentration, the curing time, and the size of the beads. The values found were $2.13 \%$ for $\mathrm{NaAlg}$ and $2.14 \%$ for $\mathrm{CaCl}_{2}$.

The concentration of sodium alginate affects the porosity of the spheres and, therefore, it affects the immobilization yield [15] [32], NaAlg concentrations lower than $3 \%$ formed more fragile hydrogel spheres, resulting in a lower immobilization yield. A fragile sphere similarly results in less enzyme entrapment in the porous structure of the beads and a large pore size, which contributes to the loss of enzyme, especially during the washing of the beads. In contrast, Rajagopalan and colleagues [33] said that a greater concentration of $\mathrm{NaAlg}$ led to the formation of a denser matrix, so that the trapping of the xylanase-rich cocktail was more effective. On the other hand, a denser matrix also signifies smaller pores, which can mean a significant reduction in the diffusion of substrate into the matrix. 


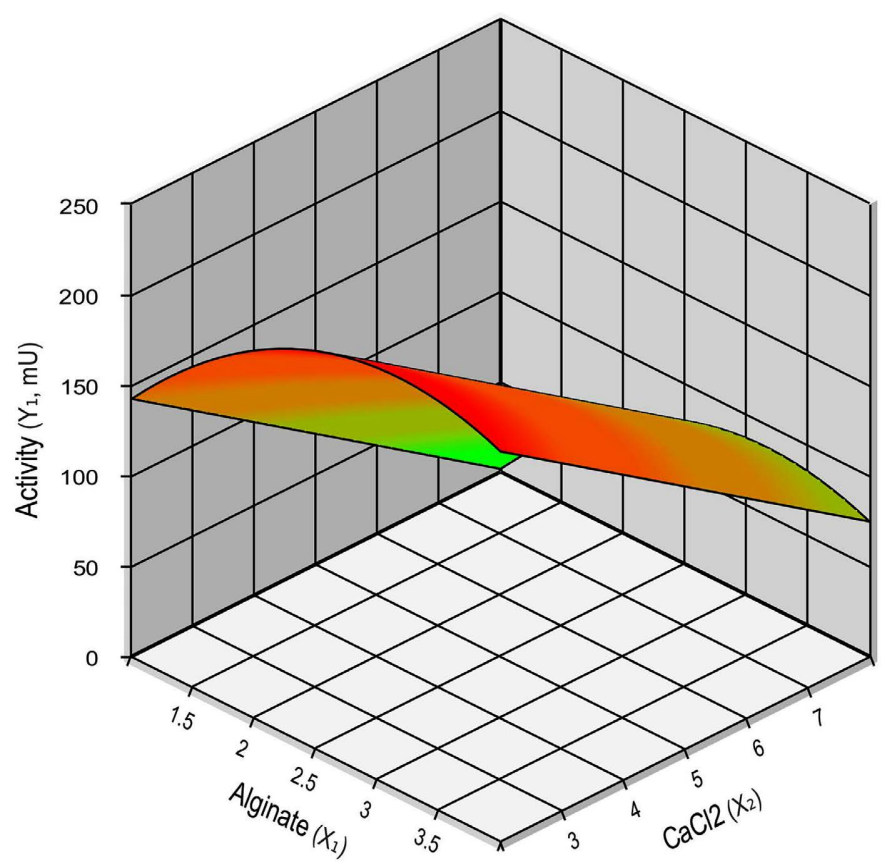

Figure 2. The response surface of the influence of $\mathrm{NaAlg}$ and $\mathrm{CaCl}_{2}$ concentrations on the immobilization process.

The effect of calcium chloride concentration was analyzed by Voo and collaborators [34]. According to the authors, the diffusion of alginate polymer was faster than $\mathrm{Ca}^{2+}$ ions at low $\mathrm{CaCl}_{2}$ concentration. Thus, the alginate polymer diffuses to the surface of the crosslinking droplet, but with an uneven distribution of the alginate polymer in the granules. On the other hand, the diffusion of $\mathrm{Ca}^{2+}$ ions was faster than that of the alginate polymer at high $\mathrm{CaCl}_{2}$ concentration. Thus, the diffusion of the alginate polymer towards the surface was limited and a more homogeneous gel structure was formed. Garai and Kumar [35] observed a maximum xylanase activity at a $3.00 \%$ alginate concentration, and the activity did not change significantly when the chloride concentration was reduced to $2.00 \%$.

Kumar and colleagues [36] studied different concentrations (0.05-0.5 M) of $\mathrm{CaCl}_{2}$ for the immobilization of purified xylanase produced by Bacillus amyloliquefaciens SK-3 and showed that $0.2 \mathrm{M} \mathrm{CaCl}_{2}$ yielded the maximum immobilization. The authors stated that further increase of the $\mathrm{CaCl}_{2}$ concentration led to a decrease in the immobilization yield. Segale and collaborators [26] also observed that the size of the spheres decreased with increasing $\mathrm{CaCl}_{2}$ concentration.

\subsection{Effect of Temperature and $\mathrm{pH}$ on the Derivative Activity Immobilized in Alginate Spheres}

A Central Rotational Composite Design $\left(\mathrm{DCCR}^{2}\right)$ was used to determine the effect of the independent variable's $\mathrm{pH}$ and temperature on the activity of the xylanase rich enzyme cocktail immobilized on alginate spheres. Higher values of 
enzymatic activity were observed in the experiments at the central points $(\mathrm{pH}=$ 6.5 and $\mathrm{T}=60^{\circ} \mathrm{C}$ ), and the lower activity of the immobilized derivative was observed in experiment 4 , at $\mathrm{pH} 8.0$ and a temperature of $80^{\circ} \mathrm{C}$ (Figure 3 ).

Both dependent variables influenced the activity in its quadratic form, and the mathematical model that best represented the behavior of the enzyme activity as a function of temperature and $\mathrm{pH}$, within the region evaluated by the Central Compound Planning, is expressed in Equation (2) according to regression values and Pareto graphs. By ANOVA analysis of variance, the F-value $=14.9$ was higher than the tabled value (4.46), indicating that the model was statistically significant.

$$
Y_{1}=203.26-56.22 x_{1}^{2}-102.39 x_{2}^{2}
$$

There is a temperature limit for each enzyme and above which protein denaturation by heat is gradually observed. The temperature at which activity levels are maximum is often referred to as the optimum temperature [37].

Bibi and colaborators [15] observed that the ideal temperature for maximum catalysis of free and immobilized endo- $\beta$-1,4-xylanase in alginate spheres did not vary; its value was $50^{\circ} \mathrm{C}$. Optimum temperatures of $40^{\circ} \mathrm{C}$ and $45^{\circ} \mathrm{C}$ were recorded by Pal and Khanum [19] for the xylanase produced by Aspergillus niger DFR-5, both soluble and covalently immobilized in alginate with glutaraldehyde, respectively. The increase in the ideal temperature might be the result of improvements in enzymatic rigidity after immobilization by covalent bonding. This behavior has also been observed in other studies, but the extent of displacement varied from matrix to matrix and with the type of interaction between the enzyme and the matrix [38] [39].

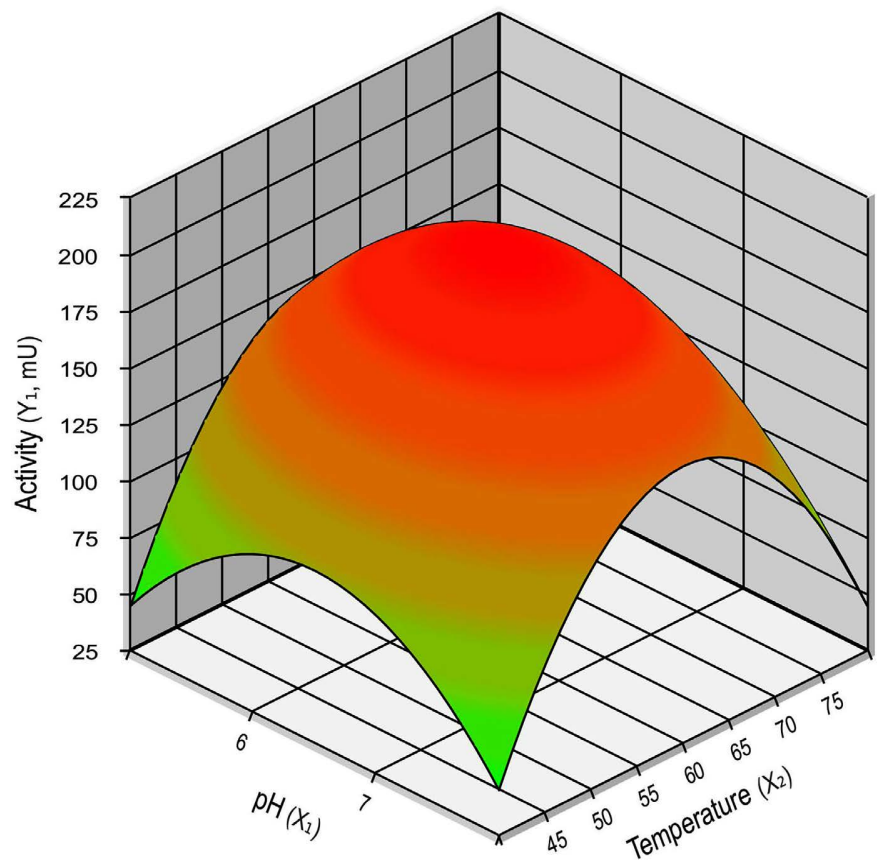

Figure 3. The response surface of the influence of $\mathrm{pH}$ and temperature on the derivative activity immobilized in alginate spheres. 
Studies with filamentous fungi have described optimal temperatures for xylanolytic activity near $40^{\circ} \mathrm{C}$ and $60^{\circ} \mathrm{C}$ [40]. Some commercial xylanases, such as Sumizyme, Multifect XL, Pulpzyme and Cartazyme, also produced by fungi, present an excellent activity in this temperature range [37]. Comparing the result obtained in this study, the temperature of $60^{\circ} \mathrm{C}$ is in the upper range of the values obtained from the literature for commercial enzymes.

Pal and Khanum [19] found that the optimal $\mathrm{pH}$ values of free and immobilized xylanases in alginate spheres activated with glutaraldehyde were 5.0 and 5.5 , respectively. This change in the optimum $\mathrm{pH}$ of $0.5 \mathrm{pH}$ units for the immobilized enzyme might be the result of the change in support environment, which further influenced the protein-support interaction and activity according to Ortega et al. [41]. An effect on the optimum $\mathrm{pH}$ of the enzyme because of the interaction of the support material with the charged amino acids of the enzymes was observed during immobilization.

\subsection{The Effect of Temperature on the Stability of Xylanolytic Enzyme Immobilized on Alginate Spheres}

When incubating the soluble and immobilized enzyme extract at $50^{\circ} \mathrm{C}$, the soluble enzyme retained $80 \%$ of its activity during the first hour, $60 \%$ until the third hour, decreasing to $20 \%$ of the initial activity near the fifth hour. This activity was maintained throughout nearly the whole experiment until $24 \mathrm{~h}$ of incubation. The enzyme immobilized in alginate spheres decreased to $60 \%$ of the initial activity during the first hour of incubation, reaching values close to $10 \%$ after seven hours of incubation. This value was maintained during $24 \mathrm{~h}$. In general, the soluble and immobilized cocktail rich in xylanase had a relatively similar behavior at this temperature (Figure 4(A)).

When testing the stability of both systems at $60^{\circ} \mathrm{C}$, the residual activity of the soluble enzyme practically disappeared after five hours of incubation, whereas the immobilized enzyme retained $70 \%$ of the initial activity, presenting a relative activity value near $40 \%$ after 14 hours of incubation and a small drop in 24 hours (Figure 4(B))

The enzymes in solution behaved similarly after incubation for 10 hat $70^{\circ} \mathrm{C}$. However, the immobilized enzyme retained about $50 \%$ of the activity during the first five hours. The decrease in the activity of the soluble enzyme was more accentuated, and no significant activity was observed at the end of this period (Figure 4(C)).

The stability of the enzyme at higher temperatures remains a significant requirement for different industries for them to reuse the catalyst more efficiently. Enzymatic stability refers to the ability of enzymes to maintain certain spatial structures for catalysis during operational and storage processes [42].

Comprehensive studies have revealed that the mechanisms that affect enzyme stability are complicated by multiple interactions, including hydrophobic bonds, hydrogen bonds, ionic bonds, protein surface charge, disulfide bonds and metal 

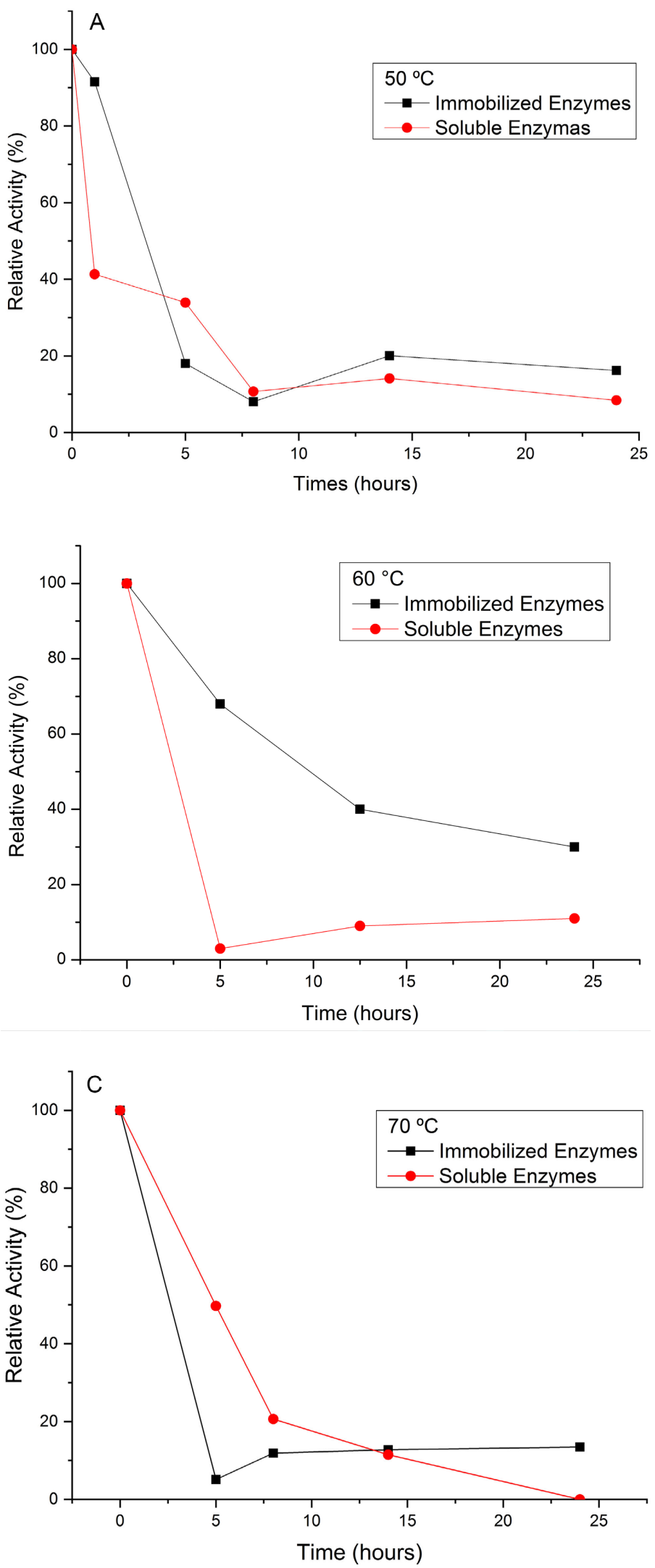

Figure 4. The effect of temperature on the stability of xylanolytic enzyme immobilized on alginate spheres. (A) $50^{\circ} \mathrm{C}$, (B) $60^{\circ} \mathrm{C}$, (C) $70^{\circ} \mathrm{C}$. 
ions. These interactions result from a combination of the amino acids composition of enzymes and several other factors. Because the stability of the enzyme is affected by several factors, there is no uniform rule to guide strategies for its improvement [43]. The improved thermal stability can be attributed to the nature and type of the matrix, which could prevent conformational changes and, in turn, stabilize the enzyme's activity at different temperatures [36].

Chen et al. [43] observed that xylanase immobilized in chitosan activated with glutaraldehyde had a greater residual activity than that of the free enzyme at temperatures of $50^{\circ} \mathrm{C}$ and $55^{\circ} \mathrm{C}$. The same result was obtained by Milessi et al. [44] when they immobilized the recombinant endoxylanase from Bacillus subtillis.

Jampala et al. [20] suggested that the decrease between $50^{\circ} \mathrm{C}$ and $90^{\circ} \mathrm{C}$ in the activity of xylanase immobilized in alginate is probably due to conformational changes in the enzyme. Surprisingly, the authors were able to maintain $75 \%$ of the activity at extreme temperatures, suggesting that xylanase was highly active and stable in the alginate matrix, when compared with other matrices tested.

Kumar et al. [36] observed a gradual decline in the relative activity at high temperature of xylanase produced from Bacillus amyloliquefaciens SK-3 both in its soluble form and immobilized in alginate spheres. However, it was observed that immobilized xylanase was able to withstand a wide range of temperatures for a relatively longer period than the free enzyme. According to the author, the increased temperature stability of the immobilized enzyme might be the result of an improvement in the rigidity of the enzyme after immobilization by covalent bonding.

The thermal stability of free and immobilized endo- $\beta$-1,4-xylanase from Geobacillus stearothermophilus KIBGE-IB29 was investigated. The free enzyme was more stable at $40^{\circ} \mathrm{C}$, whereas better results were observed for the immobilized conjugate at $50^{\circ} \mathrm{C}$ and $60^{\circ} \mathrm{C}$. At temperatures of $70^{\circ} \mathrm{C}$ and $80^{\circ} \mathrm{C}$, the activities of both forms were lost [15].

\subsection{The Effect of Glucose and Xylose on the Activity of the Cocktail Rich in Xylanase Immobilized on Alginate Spheres}

For the concentration of $5 \mathrm{mM}$ of xylose the activity of the immobilized cocktail rich in xylanase was activated by $23 \%$, whereas for $0.5 \mathrm{mM}$ glucose, no change in the activity was observed. In all the other cases, inhibition of the enzymatic catalysis occurred, the most accentuated values being with $10 \mathrm{mM}$ xylose, which reduced the reference activity by $50 \%$, that is, without the addition of the monosaccharides to the enzymatic medium (Figure 5).

In the case of hydrolysis of lignocellulosic material such as xylan and cellulose, the monomers formed are xyloses and glucoses, which are the targets in this study. According to Amani et al. [45], a decrease in the activity of certain enzymes in the presence of an easily metabolized substrate is called catabolic repression. The authors reported that the addition of glucose suppressed the activity of xylanase from Bacillus pumilus. The degree of inhibition depended on the concentration used in the reaction. 


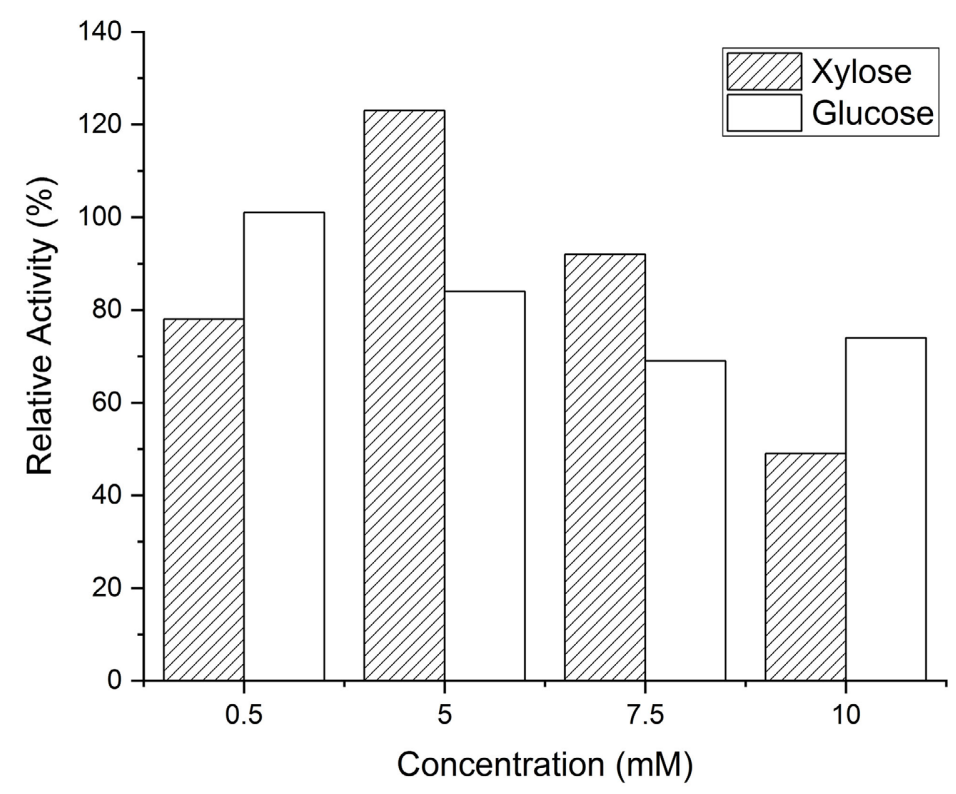

Figure 5. The effect of glucose and xylose on the activity of the cocktail rich in xylanase immobilized on alginate spheres.

\subsection{Recycling of the Immobilized Cocktail Rich in Xylanase}

When the recycled immobilized derivatives were used to hydrolyze xylan, the activity dropped $40 \%$ relative to the initial activity after the first cycle. The activity fell to $10 \%$ after six cycles (Figure 6 ).

Kumar et al. [36] obtained a 50\% retention of activity for immobilized spheres for up to five cycles; the activity decreased in additional cycles. The loss of activity of the entrapped enzyme might be due to the leakage of the enzyme from the calcium alginate spheres because of washing the spheres at the end of each cycle or to conformational changes resulting from repeated uses [46].

By immobilizing xylanase in a modified superparamagnetic graphene oxide nanocomposite, $40 \%$ residual activity was achieved after eight cycles for the best system conditions. The author observed a sharp decline in enzyme activity in the second cycle for all the conditions studied, which could be related to leaching of the enzyme. Leaching is due to the lack of binding forces between the immobilized components (enzyme and support) caused by repeated use. In addition, the unceasing encounter of the substrate with the active site of the immobilized enzyme causes distortion and leads to loss of activity [47].

Bhushan et al. [27] performed a study with xylanases immobilized in alginate spheres and in alginate spheres activated with glutaraldehyde. They observed that there was no appreciable loss of activity for up to four cycles, but then the activity began to decrease up to twelve cycles. Based on the xylanase activity, Rajagopalan et al. [33] estimated that more than $65 \%$ of the activity of xylanase immobilized on the spheres leached after three reaction cycles. To reduce leaching of xylanase and improve the rigidity of alginate beads, additives such as silica gel, chitosan and pectin could be tested. 


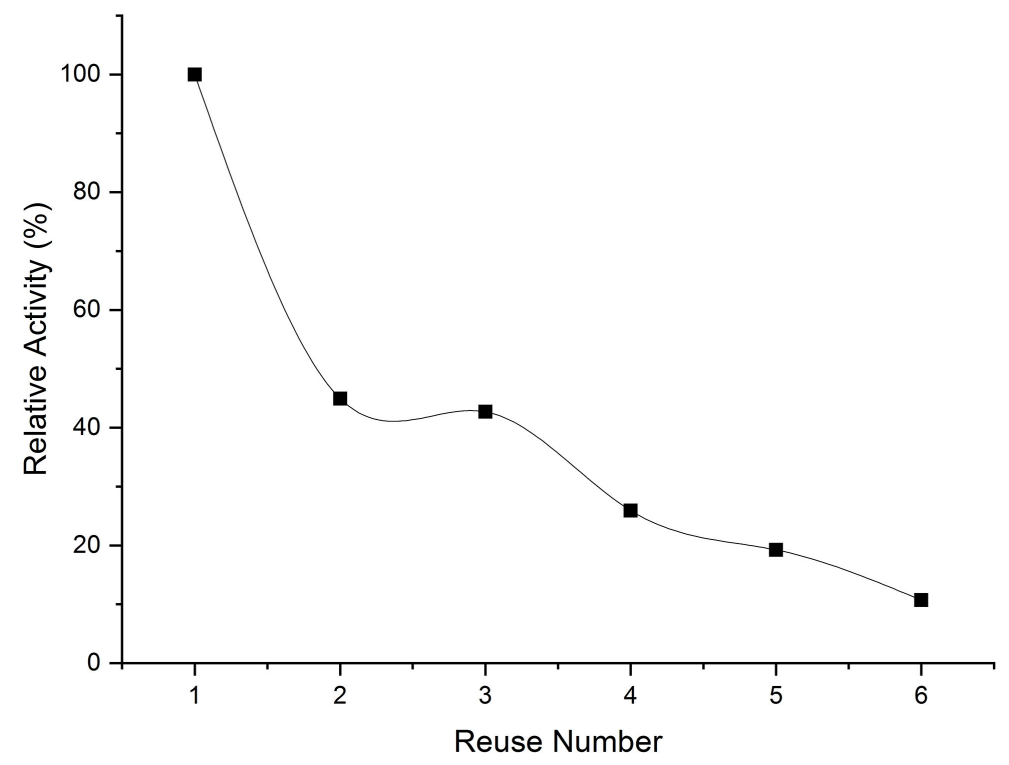

Figure 6. Recycling of the immobilized cochtail rich in xylanase.

\subsection{Storage Test}

When the activities of soluble and immobilized xylanase were determined after 75 days of storage at $4^{\circ} \mathrm{C}$, the soluble xylanolytic activity was about $80 \%$ of the initial activity, whereas the activity of the extract immobilized in alginate increased by $50 \%$ (Figure 7 ).

According to Jampala et al. [20], the main reason for the decline in xylanase actiyity during storage might be due to the conformational variation of the active xylanase sites. In their study, more than $70 \%$ of the residual activity was retained after ninety days of storage. Thus, the encapsulation of xylanase in the NaAlg spheres significantly prevented the denaturation of the enzyme and preserved the activity. Najafabadi et al. [47] stored the soluble and immobilized enzymes, and $35 \%$ of the activity for immobilized xylanase and $20 \%$ for soluble xylanase were retained after 90 days.

\subsection{Hydrolysis of Sugarcane Bagasse by a Soluble Cocktail Rich in Xylanase and Immobilized in Alginate Spheres}

The hydrolysis of in natural sugarcane bagasse by the xylanase-rich cocktail immobilized in alginate spheres yielded a greater quantity of reducing sugars. In addition, the degradation of sugarcane bagasse was more accentuated during the first eight hours of incubation (Figure 8). After enzymatic hydrolysis, the bagasse that resulted from the reaction catalyzed with the immobilized cocktail had a lighter color than the bagasse that was in contact with the soluble extract. This fact suggests a possible application in the pulp and paper industry in the bleaching process.

Finally, the fresh bagasse was microscopically analyzed, treated with the soluble cocktail and immobilized in alginate spheres to verify the state of the sugarcane fibers. The photos from Scanning Electron Microscopy. The sugarcane 
fibers are almost intact in the in natura bagasse (Figure 9(A)), whereas the fibers from the residue treated with the enzyme extract or with alginate spheres are less uniform, that is, more extensively degraded (Figure $9(B)$ and Figure $9(C)$ ). The xylanolytic cocktail produced by the filamentous fungus Fusarium sp. EA 1.3.1 immobilized in alginate spheres has a potential for hydrolyzing lignocellulosic material, without pre-treatment, to form sugars that can be fermented to generate second generation ethanol.

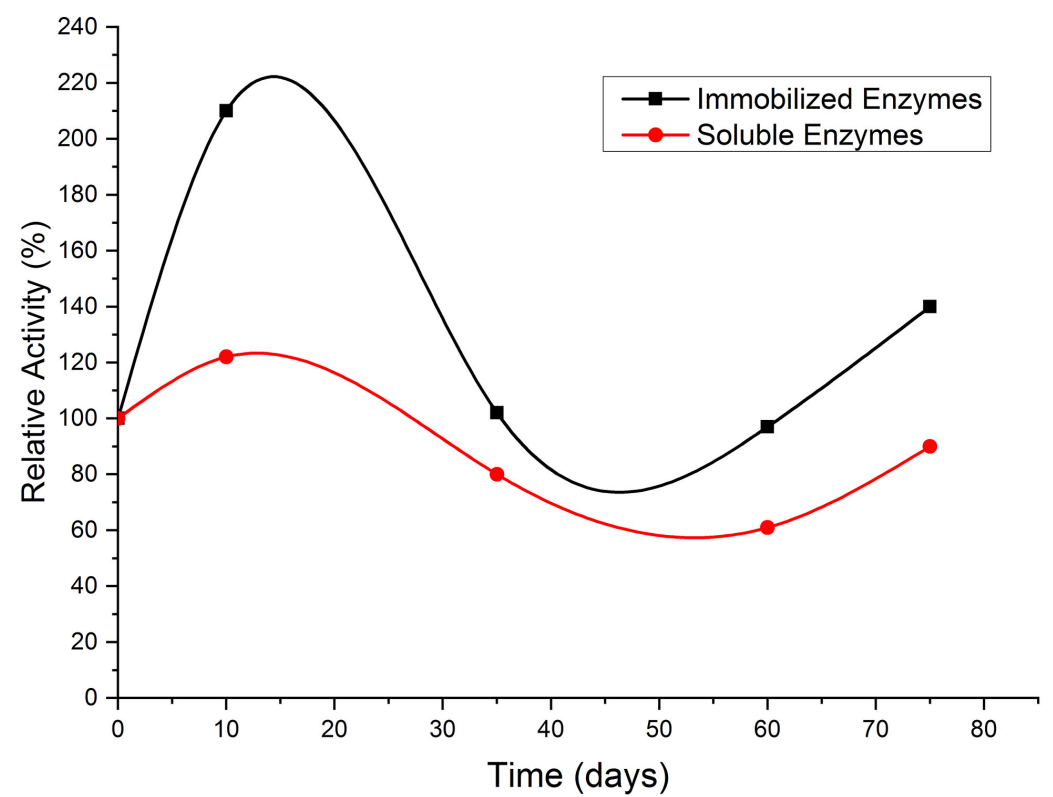

Figure 7. Determination of soluble and immobilized xylanolytic activity in alginate spheres after storage at $4^{\circ} \mathrm{C}$.

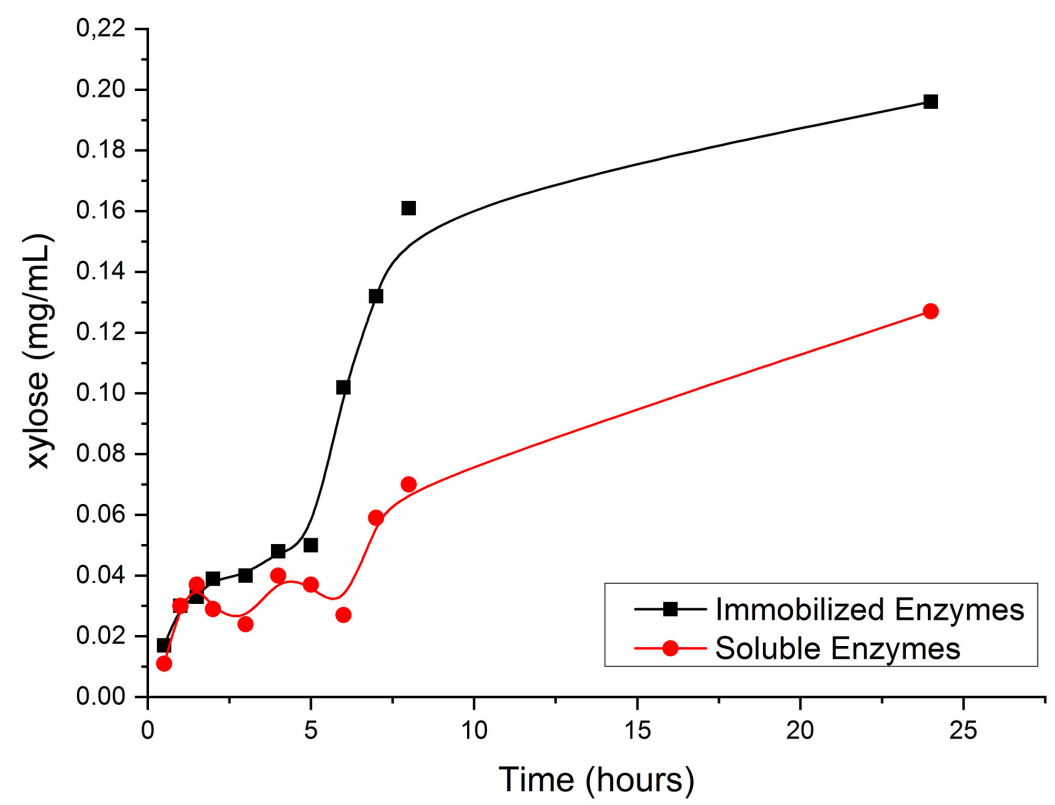

Figure 8. Hydrolysis of sugarcane bagasse by a soluble cocktail rich in xylanase and immobilized in alginate spheres. 

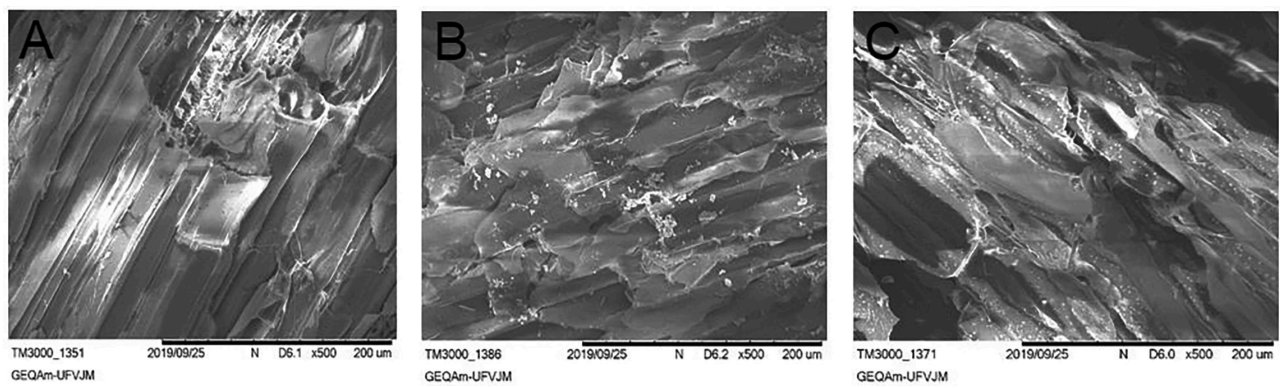

Figure 9. Sugar cane bagasse image in Scanning Electron Microscopy. (A) in natura, (B) after hydrolysis with soluble enzyme, (C) after hydrolysis with immobilized enzyme.

\section{Conclusion}

The possibility of immobilizing the cocktail rich in xylanase produced by the fungus Fusarium sp. EA 1.3.1 in alginate spheres in a simple and inexpensive way, using a thick glass rod, with $3.14 \%$ and $2.10 \%$ concentrations of sodium alginate and calcium chloride, respectively, was demonstrated. The optimum temperature and $\mathrm{pH}$ obtained from a factorial design for the enzymatic reaction of immobilized xylanase were found to be $65^{\circ} \mathrm{C}$ and $6.5^{\circ} \mathrm{C}$, respectively. It was shown that xylanase immobilized in alginate spheres was more stable than the soluble enzyme at $60^{\circ} \mathrm{C}$ and that xylose and glucose inhibited the enzymatic activity of immobilized xylanase in concentrations above $5 \mathrm{mM}$. The immobilized spheres could be re-used up to six times, and there was an increase in activity of the immobilized enzyme after storing for seventy-five days, at $4^{\circ} \mathrm{C}$, whereas the soluble enzyme maintained its initial activity. The fact that the tested enzyme maintains its stability at temperature and $\mathrm{pH}$ close to those used in real industrial processes $\left(50^{\circ} \mathrm{C}\right.$ to $65^{\circ} \mathrm{C} ; 5.5 \mathrm{pH}$ to $\left.6.5 \mathrm{pH}\right)$, in addition to the gain in its reuse, which does not occur in current processes since the enzymes are free in the solution, are expressive and advantageous results from an industrial point of view. When the enzymatic hydrolysis of in natural sugarcane bagasse was performed, a larger amount of reducing sugars was obtained when the bagasse reacted in the presence of the immobilized conjugate, indicating possible catalytic gains when using the proposed immobilization method and its application in the second generation ethanol manufacturing process.

\section{Acknowledgements}

This study was financed in part by Coordenação de Aperfeiçoamento de Pessoal de Nível Superior-Brasil (CAPES)_Finance Code 001. Authors wish to thank the support from LMMA sponsored by FAPEMIG (CEX-112-10), SECTES/MG and RQ-MG (FAPEMIG: CEX-RED-00010-14).

\section{Conflicts of Interest}

The authors declare no conflicts of interest regarding the publication of this paper. 


\section{References}

[1] Singh, D., Sharma, D., Soni, S.L., Sharma, S. and Kumari, D. (2019) Chemical Compositions, Properties, and Standards for Different Generation Biodiesels: A Review. Fuel, 253, 60-71. https://doi.org/10.1016/j.fuel.2019.04.174

[2] Liu, H., Wang, X., Yangyi, W., Zhang, X., Jin, C. and Zheng, Z (2019) Effect of Diesel/PODE/Ethanol Blends on Combustion and Emissions of a Heavy Duty Diesel Engine. Fuel, 257, Article ID: 116064. https://doi.org/10.1016/j.fuel.2019.116064

[3] Carpio, L.G.T. and Souza, F.S. (2017) Optimal Allocation of Sugarcane Bagasse for Producing Bioelectricity and Second Generation Ethanol in Brazil: Scenarios of Cost Reductions. Renewable Energy, 111, 771-780. https://doi.org/10.1016/j.renene.2017.05.015

[4] Sani, S., Kaisan, M., Kulla, D., Obi, A., Jibrin, A. and Ashok, B. (2018) Determination of Physico Chemical Properties of Biodiesel from Citrullus lanatus Seeds Oil and Diesel Blends. Industrial Crops and Products, 12, 702-708. https://doi.org/10.1016/j.indcrop.2018.06.002

[5] Shanmugam, S., Krishnaswamy, S., Chandrababu, R., Veerabagu, U., Pugazhendhi, A. and Mathimani, T. (2020) Optimal Immobilization of Trichoderma asperellum laccase on Polymer Coated Fe3O4@SiO2 Nanoparticles for Enhanced Biohydrogen Production from Delignified Lignocellulosic Biomass. Fuel, 273, Article ID: 117777. https://doi.org/10.1016/j.fuel.2020.117777

[6] Song, Y., Lee, Y.G., Cho, E.J. and Bae, H.J. (2020) Production of Xylose, Xylulose, Xylitol, and Bioethanol from Waste Bamboo Using Hydrogen Peroxicde-Acetic Acid Pretreatment. Fuel, 278, Article ID: 118247.

https://doi.org/10.1016/j.fuel.2020.118247

[7] Baksi, S., Sarkar, U., Mukherjee, S., Kuniyal, J.C. and Saha, S. (2020) High-Temperature Tolerant Enzyme Based Extraction of Lignocellulose Derived C5 and C6 Sugars for the Integrated Production of a Promising Supplement for a Diesel/Jet-Engine Fuel. Fuel, 275, Article ID: 117740. https://doi.org/10.1016/j.fuel.2020.117740

[8] Carvalho, D.J., Moretti, R.R., Colodette, J.L. and Bizzo, W.A. (2020) Assessment of the Self-Sustained Energy Generation of an Integrated First and Second Generation Ethanol Production from Sugarcane through the Characterization of the Hydrolysis Process Residues. Energy Conversion and Management, 203, Article ID: 112267. https://doi.org/10.1016/j.enconman.2019.112267

[9] Claes, A., Deparis, Q., Foulquié-Moreno, R.M. and Thevelein, J.M. (2020) Simultaneous Secretion of Seven Lignocellulolytic Enzymes by an Industrial Second-Generation Yeast Strain Enables Efficient Ethanol Production from Multiple Polymeric Substrates. Metabolic Engineering, 59, 131-141. https://doi.org/10.1016/j.ymben.2020.02.004

[10] Esmaeili, S.A.H., Sobhani, A., Szmerekovsky, J., Dybing, A. and Pourhashem, G. (2020) First-Generation vs. Second-Generation: A Market Incentives Analysis for Bioethanol Supply Chains with Carbon Policies. Applied Energy, 277, Article ID: 115606. https://doi.org/10.1016/j.apenergy.2020.115606

[11] Nuanpeng, S., Thanonkeo, S., Klanrit, P. and Thanonkeo, P. (2018) Ethanol Production from Sweet Sorghum by Saccharomyces cerevisiae DBKKUY-53 Immobilized on Alginate-Loofah Matrices. Brazilian Journal of Microbiology, 49, 372-383. https://doi.org/10.1016/j.bjm.2017.12.011

[12] Mateo, C., Grazú, V., Pessela, B., Montes, T., Palomo, J., Torres, R., López, F., Fernández, R. and Guisán, J. (2007) Advances in the Design of New Epoxy Supports for Enzyme Immobilization-Stabilization. Biochemical Society Transactions, 35, 
1593-1601. https://doi.org/10.1042/BST0351593

[13] Goverdhan, C.P. (1999) Crosslinking of Enzymes Stability and Performance. Current Opinion in Biotechnology, 10, 331-335.

https://doi.org/10.1016/S0958-1669(99)80060-3

[14] Maurich, A., Komesu, A., Adriano, W., Tardioli, P. and Giordano, R. (2010) Immobilization and Stabilization of Xylanase by Multipoint Covalent Attachment on Agarose and on Chitosan Supports. Applied Biochemistry and Biotechnology, 161, 455-467. https://doi.org/10.1007/s12010-009-8897-0

[15] Bibi, Z., Qader, S.A. and Aman, A. (2015) Calcium Alginate Matrix Increases the Stability and Recycling Capability of Immobilized Endo- $\beta$-1,4-xylanase from Geobacillus stearothermophilus KIBGE-IB29. Extremophiles, 19, 819-827. https://doi.org/10.1007/s00792-015-0757-y

[16] Kirupa Sankar, M., Ravikumar, R., Naresh Kumar, M. and Sivakumar, U. (2018) Development of Co-Immobilized Tri-Enzyme Biocatalytic System for One-Pot Pretreatment of Four Different Perennial Lignocellulosic Biomass and Evaluation of Their Bioethanol Production Potential. Bioresource Technology, 269, 227-236. https://doi.org/10.1016/j.biortech.2018.08.091

[17] Bernal, C., Rodríguez, K. and Martínez, R. (2018) Integrating Enzyme Immobilization and Protein Engineering: An Alternative Path for the Development of Novel and Improved Industrial Biocatalysts. Biotechnology Advances, 36, 1470-1480. https://doi.org/10.1016/j.biotechadv.2018.06.002

[18] Saha, K., Verma, P., Sikder, J., Chakraborty, S. and Curcio, S. (2019) Synthesis of Chitosan-Cellulase Nanohybrid and Immobilization on Alginate Beads for Hydrolysis of Ionic Liquid Pretreated Sugarcane Bagasse. Renewable Energy, 133, 66-76. https://doi.org/10.1016/j.renene.2018.10.014

[19] Pal, A. and Khanum, F. (2011) Covalent Immobilization of Xylanase on Glutaraldehyde Activated Alginate Bead Using Response Surface Methodology: Characterization of Immobilized Enzyme. Process Biochemistry, 46, 1315-1322. https://doi.org/10.1016/j.procbio.2011.02.024

[20] Jampala, P., Preethi, M., Ramanujam, S., Harish, B., Uppuluri, K. and Anbazhaagan, V. (2017) Immobilization of Levan-Xylanase Nanohybrid on an Alginate Bead Improves Xylanase Stability at Wide $\mathrm{pH}$ and Temperature. International Journal of Biological Macromolecules, 95, 843-849. https://doi.org/10.1016/j.ijbiomac.2016.12.012

[21] Bilal, M., Rasheedb, T., Zhao, Y., Iqbal, H.M.N. and Cui, J. (2018) “Smart” Chemistry and Its Application in Peroxidase Immobilization Using Different Support Materials. International Journal of Biological Macromolecules, 119, 278-290. https://doi.org/10.1016/j.ijbiomac.2018.07.134

[22] Emerson, R. (1941) An Experimental Study of the Life Cycles and Taxonomy of Allomyces. Lloydia, 4, 77-144.

[23] Lee, B.B., Ravindra, P. and Chan, E.S. (2013) Size and Shape of Calcium Alginate Beads Produced by Extrusion Dripping. Chemical Engineering Tecnology, 36, 1627-1642. https://doi.org/10.1002/ceat.201300230

[24] Mandal, S., Kumar, S., Krishnamoorthy, B. and Kumar, B.S. (2010) Development and Evaluation of Calcium Alginate Beads Prepared by Sequential and Simultaneous Methods. Brazilian Journal of Pharmaceutical Sciences, 46, 785-793. https://doi.org/10.1590/S1984-82502010000400021

[25] Miller, G.L. (1959) Use of Dinitrosalicylic Acid Reagente for Determination of Reducing Sugar. Analytical Chemistry, 31, 426-428. 
https://doi.org/10.1021/ac60147a030

[26] Segale, L., Giovannelli, L., Mannina, P. and Pattarino, F. (2016) Calcium Alginate and Calcium Alginate-Chitosan Beads Containing Celecoxib Solubilized in a SelfEmulsifying Phase. Scientifica, 2016, Article ID: 5062706.

https://doi.org/10.1155/2016/5062706

[27] Bhushan, B., Pal, A. and Jain, V. (2015) Improved Enzyme Catalytic Characteristics upon Glutaraldehyde Cross-Linking of Alginate Entrapped Xylanase Isolated from Aspergillus flavus MTCC 9390. Enzyme Research, 2015, Article ID: 210784. https://doi.org/10.1155/2015/210784

[28] Huang, S.L. and Lin, Y.S. (2017) The Size Stability of Alginate Beads by Different Ionic Crosslinkers. Advances in Materials Science and Engineering, 2017, Article ID: 9304592. https://doi.org/10.1155/2017/9304592

[29] Seifert, D.B. and Phillips, J.A. (1997) Porous Alginate-Poly(ethylene glycol) Entrapment System for the Cultivation of Mammalian Cells. Biotechnology Progress, 13, 569-576. https://doi.org/10.1021/bp970071a

[30] Sukri, S.S. and Sakinah, A. (2017) Effects of Support Matrix for Xylanase Immobilisation on Alginate Hydrogel Beads. International Journal of Engineering Technology and Sciences, 7, 1-8.

[31] Kumar, S., Dwevedi, A. and Kayastha, A. (2019) Immobilization of Soybean (Glycine max) Urease on Alginate and Chitosan Beads Showing Improved Stability: Analytical Applications. Journal of Molecular Catalysis B: Enzymatic, 58, 138-145. https://doi.org/10.1016/j.molcatb.2008.12.006

[32] Lotfipour, F., Mirzaeei, S. and Maghsoodi, M. (2012) Evaluation of the Effect of $\mathrm{CaCl}_{2}$ and Alginate Concentrations and Hardening Time on the Characteristics of Lactobacillus acidophilus Loaded Alginate Beads Using Response Surface Analysis. Advanced Pharmaceutical Bulletin, 2, 71-78. https://doi.org/10.1100/2012/680108

[33] Rajagopalan, G., Shanmugavelu, K. and Yang, K.L. (2016) Production of Xylooligosaccharides from Hardwood Xylan by Using Immobilized Endoxylanase of Clostridium Strain BOH3. The Royal Society of Chemistry, 6, 81818-81825. https://doi.org/10.1039/C6RA17085D

[34] Voo, W.P., Ooi, C.W., Islam, A., Tey, B.T. and Chan, E.S. (2016) Calcium Alginate Hydrogel Beads with High Stiffness and Extended Dissolution Behaviour. European Polymer Journal, 75, 343-353. https://doi.org/10.1016/j.eurpolymj.2015.12.029

[35] Garai, D. and Kumar, V. (2013) A Box-Behnken Design Approach for the Production of Xylanase by Aspergillus candidus under Solid State Fermentation and Its Application in Saccharification of Agro Residues and Parthenium hysterophorus L. Industrial Crops and Products, 44, 352-363.

https://doi.org/10.1016/j.indcrop.2012.10.027

[36] Kumar, S., Haq, I., Yadav, A., Prakash, J. and Raj, A. (2016) Immobilization and Biochemical Properties of Purified Xylanase from Bacillus amyloliquefaciens SK-3 and Its Application in Kraft Pulp Biobleaching. Journal of Clinical Microbiology and Biochemical Technology, 2, 26-34. https://doi.org/10.17352/jcmbt.000012

[37] Polizeli, M., Rizzatti, A., Monti, R., Terenzi, H., Jorge, J. and Amorim, D. (2005) Xylanases from Fungi: Properties and Industrial Applications Review. Applied Microbiology and Biotechnology, 67, 577-591. https://doi.org/10.1007/s00253-005-1904-7

[38] Gawande, P.V. and Kamat, M.Y. (1998) Preparation, Characterization and Application of Aspergillus sp. Xylanase Immobilized on Eudragit S-100. Journal of Biotechnology, 66, 165-175. https://doi.org/10.1016/S0168-1656(98)00146-1 
[39] Ai, Z., Jiang, Z., Li, L., Deng, W., Kusakabe, I. and Li, H. (2005) Immobilization of Streptomyces olivaceoviridis E-86 Xylanase on Eudragit S-100 for Xylo-Oligosaccharide Production. Process Biochemistry, 40, 2707-2714.

https://doi.org/10.1016/j.procbio.2004.12.006

[40] Chen, G.G., Ming, X., Guan, Y., Peng, F., Yao, C.L. and Sun, R.C. (2016) High Strength Hemicellulose-Based Nanocomposite Film for Food Packaging Applications. ACS Sustainable Chemistry \& Engineering, 4, 1985-1993.

https://doi.org/10.1021/acssuschemeng.5b01252

[41] Ortega, N., Perez, M.M., Pilar, M.C. and Busto, M.D. (2009) Neutrase Immobilization on Alginate-Glutaraldehyde Beads by Covalent Attachment. Journal of Agricultural and Food Chemistry, 57, 109-115. https://doi.org/10.1021/jf8015738

[42] Liu, Q., Xun, G. and Feng, Y. (2019) The State-of-Art Strategies of Protein Engineering for Enzyme Stabilization. Biotechnology Advances, 37, 530-537.

https://doi.org/10.1016/j.biotechadv.2018.10.011

[43] Chen, H., Liu, L., Lv, S., Liu, X., Wang, M., Song, A. and Jia, X. (2007) Immobilization of Aspergillus niger Xylanase on Chitosan Using Dialdehyde Starch as a Coupling Agent. Applied Biochemistry and Biotechnology, 162, 24-32.

https://doi.org/10.1007/s12010-009-8790-x

[44] Milessi, T.S., Kopp, W., Rojas, M., Manrich, A., Neto, A.B., Tardioli, P.W. and Giordano, R.L. (2015) Immobilization and Stabilization of an Endoxylanase from Bacillus subtilis (XynA) for Xylooligosaccharides (XOs) Production. Catalysis Today, 259, 130-139. https://doi.org/10.1016/j.cattod.2015.05.032

[45] Amani, M.D., Ahwany, S., Amani, S. and Youssef, S. (2007) Xylanase Productionby Bacillus pumilus. Optimization by Statistical and Immobilization Methods. Research Jounal of Agriculture and Biological Science, 3, 727-737.

[46] Mateo, C., Palomo, J.M., Lorente, G.F., Guisan, J.M. and Lafuente, R.F. (2007) Improvement of Enzyme Activity, Stability and Selectivity via Immobilization Techniques. Enzyme and Microbial Technology, 40, 1451-1463.

https://doi.org/10.1016/j.enzmictec.2007.01.018

[47] Najafabadi, V., Kafrani, A. and Bordbar, A. (2018) Xylanase Immobilization on Modified Superparamagnetic Graphene Oxide Nanocomposite: Effect of PEGylation on Activity and Stability. International Journal of Biological Macromolecules, 107, 418425. https://doi.org/10.1016/j.ijbiomac.2017.09.013 